
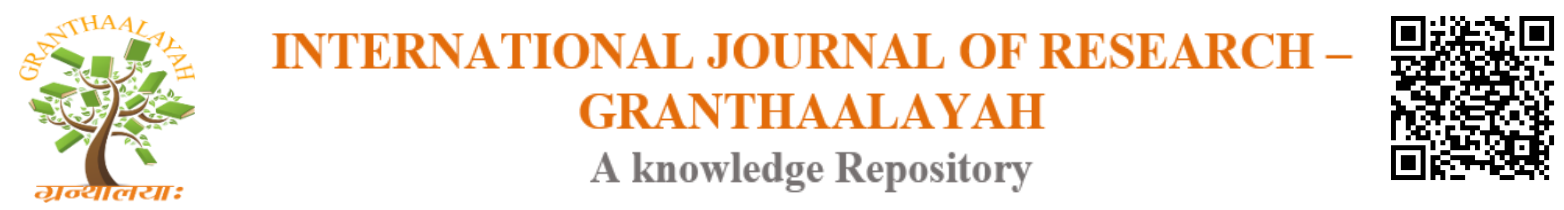

Science

\title{
THE PREDICTION OF THE THERMOHYDROGRAVIDYNAMIC THEORY CONCERNING THE FIRST SUBRANGE IN 2018 OF THE STRONGEST INTENSIFICATIONS OF THE GLOBAL NATURAL PROCESSES SINCE 26 FEBRUARY AND BEFORE 24 AUGUST, 2018
}

\author{
Dr. Sergey V. Simonenko *1 \\ ${ }^{* 1}$ V.I. Il'ichev Pacific Oceanological Institute, Far Eastern Branch of Russian Academy of \\ Sciences, Vladivostok, Russia
}

\begin{abstract}
The article presents (on 28 February, 2017) the prediction (made on 25 February, 2018) of the established global prediction thermohydrogravidynamic principle (of the developed thermohydrogravidynamic theory containing the cosmic geophysics and the cosmic seismology based on the author's generalization of the first law of thermodynamics for non-stationary cosmic gravitation of the Solar System and our Galaxy) concerning the first subrange (in 2018) of the strongest intensifications (since 26 February and before 24 August, 2018) of the global seismotectonic, volcanic, climatic and magnetic processes of the Earth determined by the minimal (in 2018 near 26 May, 2018) combined integral energy gravitational influence on the internal rigid core of the Earth (and on the Earth as a whole) of the planets (Mercury, Venus, Mars and Jupiter) and the Sun due to the gravitational interactions of the Sun with Jupiter Saturn, Uranus and Neptune. The prediction is based on the established global prediction thermohydrogravidynamic principle (used for the considered real planetary configurations of the Earth and the planets of the Solar System during the range $2004 \div 2018$ ) and on the statistical analysis of the previous strongest earthquakes occurred near the calculated dates of the local minimal combined planetary and solar integral energy gravitational influences (during the range $2004 \div 2017$ ) on the internal rigid core of the Earth.
\end{abstract}

Keywords: Thermohydrogravidynamic Theory; Cosmic Seismology; Cosmic Gravitation; Seismotectonic; Volcanic and Climatic Disasters.

Cite This Article: Dr. Sergey V. Simonenko. (2018). "THE PREDICTION OF THE THERMOHYDROGRAVIDYNAMIC THEORY CONCERNING THE FIRST SUBRANGE IN 2018 OF THE STRONGEST INTENSIFICATIONS OF THE GLOBAL NATURAL PROCESSES SINCE 26 FEBRUARY AND BEFORE 24 AUGUST, 2018." International Journal of Research - Granthaalayah, 6(2), 346-365. https://doi.org/10.5281/zenodo.1199171. 


\section{Introduction}

The predictions of the strongest seismotectonic [1-4], volcanic [4, 5], climatic [4, 6, 7, 8] and geomagnetic [9-13] processes of the Earth are the urgent problems [8, 14, 15] for humankind before the founded [8, 15] increased intensifications (during the ranges $2020 \div 2026$ [8, 15], $2037.38 \div 2043.38[8,15]$ and $2055 \div 2064$ [15]) of the global natural (seismotectonic, volcanic, climatic and magnetic) processes $[8,15]$ of the Earth. We expanded the application of the thermohydrogravidynamic theory [2-4, 7, 8, 13-15] (of the global natural processes of the Earth) on the rotational coordinate system [16] ("for evidence of the tidal mechanism of maintenance of the energy and viscous-thermal dissipative turbulent structure of the mesoscale oceanic eddies" [16]), that gives the possibility to expand the thermohydrogravielectromagnetic theory [8, 13, 17] of the controlled thermonuclear reactions [13, 18-20] (related [13] with the problem [9-13] of the geomagnetic reversals) on the rotational coordinate system related with the rotating Earth. In this article, we present (to the International Journal of Research - GRANTHAALAYAH) the prognosticating deductions of the thermohydrogravidynamic theory [2-4, 7, 8, 13-15, 17] of the global natural processes concerning the different forthcoming ranges (characterized by the calculated probabilities) of the strongest intensifications of the global natural (seismotectonic, volcanic, climatic and magnetic) processes of the Earth since 26 February, 2018 and before 24 August, 2018.

In Section 2 we present the established generalized formulation (1) of the first law of thermodynamics [2-4, 7, 8, 13-15, 17, 21] for the symmetric stress tensor $\mathbf{T}$ [22] and the established [8, 15] global prediction thermohydrogravidynamic principles (5) and (6) determining the maximal temporal intensifications of the global and regional natural (seismotectonic, volcanic, climatic and magnetic) processes of the Earth related with the maximal and minimal combined cosmic integral energy gravitational influences (5) and (6), respectively, for the time moments $\mathrm{t}=\mathrm{t}^{*}\left(\tau_{\mathrm{c}, \mathrm{r}}\right)$ and $\left.\mathrm{t}=\mathrm{t}_{*}\left(\tau_{\mathrm{c}, \mathrm{r}}\right)\right)$ on the considered internal rigid core $\tau_{\mathrm{c}, \mathrm{r}}$ (of the Earth) subjected to the combined cosmic integral energy gravitational influence of the planets of the Solar System, the Moon and the Sun (owing to the gravitational interaction of the Sun with the outer large planets).

In Section 3 we present the previous prediction [23] (based on the global prediction thermohydrogravidynamic principle (5)) concerning the strongest intensifications of the global natural (sesmotectonic, volcanic, climatic and magnetic) processes of the Earth (since 18 July, 2017 and before 26 February, 2018) determined by the maximal (for the time moment $\mathrm{t}^{*}\left(\tau_{\mathrm{c}, \mathrm{r}}, 2017\right)=2017.85$, which corresponds approximately to 7 November, 2017) combined planetary and solar integral energy gravitational influences on the internal rigid core $\tau_{c, r}$ of the Earth. In Section 3 we present also (on 28 February, 2018) the new prediction (based on the global prediction thermohydrogravidynamic principle (6)) concerning the strongest intensifications of the global natural (seismotectonic, volcanic, climatic and magnetic) processes of the Earth (since 26 February, 2018 and before 24 August, 2018) determined by the minimal (for the time moment $t_{*}\left(\tau_{\mathrm{c}, \mathrm{r}}, 2018\right)=2018.4$, which corresponds approximately to 26 May, 2018) combined planetary and solar integral energy gravitational influence on the internal rigid core $\tau_{\mathrm{c}, \mathrm{r}}$ of the Earth. 
In Section 4 we present (on 28 February, 2018) the existing facts and evidences confirming the validity of the established $[8,15,23]$ global prediction thermohydrogravidynamic principle (5) (of the thermohydrogravidynamic theory $[2-4,7,8,13-15,21,23]$ ) concerning the second subrange of the strongest (in 2017 and 2018) intensifications of the global natural (seismotectonic, volcanic and climatic) processes of the Earth since 6 August, 2017 (really, instead of "18 July, 2017" [23]) and before 26 February, 2018 [23].

In Section 5 we present the conclusions.

\section{Methodology}

Based on the general equation of continuum movement [22], the classical differential formulation [24] of the first law of thermodynamics for the one-component macrodifferential continuum element, the decomposition $\mathbf{P}=\mathrm{p} \boldsymbol{\delta}+\boldsymbol{\Pi}$ [24] for the pressure tensor $\mathbf{P}$, the viscousstress tensor $\boldsymbol{\Pi}[24]$ and the symmetric stress tensor $\mathbf{T}=-\mathbf{P}$ [22] ( $\boldsymbol{\delta}$ is the Kronecker deltatensor, $\mathrm{p}$ is the thermodynamic pressure), we derived $[2-4,7,8,13-15,17,21,23,25]$ the generalized differential formulation of the first law of thermodynamics (for individual finite continuum region $\tau$ considered in a Galilean frame of reference with respect to a Cartesian coordinate system $K$ shown on Fig. 1):

$$
\mathrm{dU}_{\tau}+\mathrm{dK}_{\tau}+\mathrm{d} \pi_{\tau}=\delta \mathrm{Q}+\delta \mathrm{A}_{\mathrm{np}, \partial \tau}+\mathrm{dG}
$$

where $\delta \mathrm{Q}$ is the classical $[22,24,26,27]$ infinitesimal change of heat across the continuum boundary surface $\partial \tau$ of the continuum region $\tau, \mathrm{dU}_{\tau}$ is the classical $[22,24,26,27]$ infinitesimal change of the internal thermal energy $\mathrm{U}_{\tau}, \mathrm{dK}_{\tau}$ is the established $[2-4,7,8,13-15$, $17,21,23]$ infinitesimal increment of the macroscopic kinetic energy $K_{\tau}[21,28]$ of the continuum region $\tau, \mathrm{d} \boldsymbol{\pi}_{\tau}$ is the established [2-4, 7, 8, 13-15, 17, 21, 23] infinitesimal increment of the gravitational potential energy $\pi_{\tau}$ determined by the potential $\psi$ of the combined (cosmic and terrestrial) non-stationary gravity field, $\delta \mathrm{A}_{\mathrm{np}, \hat{\gamma \tau}}$ is the generalized $[2-4,7,8,14,17$, $21,23]$ infinitesimal work done by non-potential terrestrial stress forces acting on the continuum boundary surface $\partial \tau$ of the continuum region $\tau$,

$$
\mathrm{dG}=\mathrm{dt} \iiint_{\tau} \frac{\partial \psi}{\partial \mathrm{t}} \rho \mathrm{dV}
$$

is the established $[2-4,7,8,13-15,17,23]$ infinitesimal combined (cosmic and terrestrial) nonstationary energy gravitational influence on the continuum region $\tau$ during the infinitesimal time interval dt. The relation (2) for $\mathrm{dG}$ takes into account the partial derivative $\partial \psi / \partial \mathrm{t}$ of the potential $\psi$ of the combined (cosmic and terrestrial) non-stationary gravitational field, the local mass density $\rho$ of the differential volume $\mathrm{dV}$ in the continuum region $\tau$. 
The generalized differential formulation (1) of the first law of thermodynamics and the relation (2) result to the following relation:

$$
\mathrm{dG}=\mathrm{dt} \iiint_{\tau} \frac{\partial \psi}{\partial \mathrm{t}} \rho \mathrm{dV}=-\mathrm{dt} \iint_{\partial \tau}\left(\mathbf{J}_{\mathrm{g}} \cdot \mathbf{n}\right) \mathrm{d} \Omega_{\mathbf{n}}
$$

Which is the theoretical foundation $[3,4,8,15,23]$ of the power $\mathbf{J}_{\mathrm{g}}$ of the gravitational energy (of the detected [1] non-relativistic classical "gravitational" waves [3, 4, 8, 15, 23] generated from the focal regions of earthquakes and from the internal rigid core $\tau_{c, r}$ of the Earth) across the surface element $d \Omega_{\mathbf{n}}$ determined by the external normal unit vector $\mathbf{n}$. This theoretical foundation is based on the relation $\left[3,4,15,17\right.$, and 23] for the divergence $\operatorname{div} \mathbf{J}_{\mathrm{g}}$ :

$$
\operatorname{div} \mathbf{J}_{\mathrm{g}}=-\rho \frac{\partial \psi}{\partial \mathrm{t}}
$$

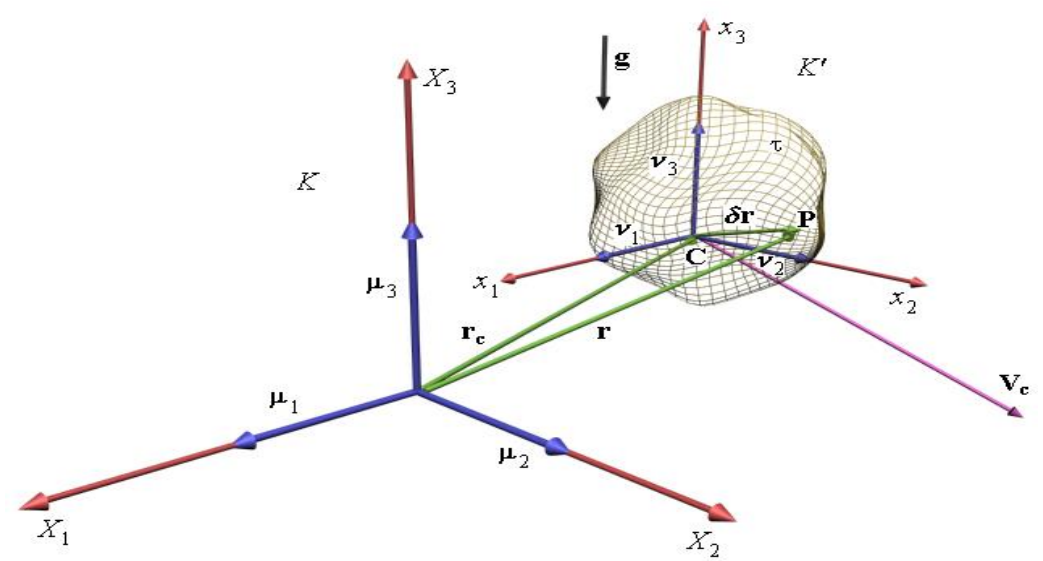

Figure 1: Cartesian coordinate system $K$ of a Galilean frame of reference and an individual finite continuum region $\tau$ subjected to the non-stationary Newtonian gravitation field and nonpotential terrestrial stress forces

Based on the generalized formulation (1) of the first law of thermodynamics (used for the internal rigid core $\tau_{\mathrm{c}, \mathrm{r}}$ of the Earth), we formulated [8, 15] the global prediction thermohydrogravidynamic principles determining the maximal temporal intensifications of the established $[8,15]$ thermohygrogravidynamic processes (in the internal rigid core $\tau_{c, r}$ and in the boundary region $\tau_{\mathrm{rf}}$ between the internal rigid core $\tau_{\mathrm{c}, \mathrm{r}}$ and the fluid core $\tau_{\mathrm{c}, \mathrm{f}}$ of the Earth considered as a whole) subjected to the combined cosmic energy gravitational influence of the planets of the Solar System, the Moon, the Sun (owing to the gravitational interaction of the Sun with the outer large planets) and our Galaxy (Milky Way) [7, 8, 14, 29]. We concluded [8, 15, 23] (based on the generalized formulation (1) of the first law of thermodynamics used for the internal rigid core $\tau_{\mathrm{c}, \mathrm{r}}$ of the Earth) that the maximal intensifications of the established thermohygrogravidynamic processes are related with the corresponding maximal intensifications of the global and regional natural (seismotectonic, volcanic, climatic and magnetic) processes of the Earth. 
The rigorous global prediction thermohydrogravidynamic principles (determining the maximal temporal intensifications near the time moments $\mathrm{t}=\mathrm{t}^{*}\left(\tau_{\mathrm{c}, \mathrm{r}}\right)$ and $\mathrm{t}=\mathrm{t}_{*}\left(\tau_{\mathrm{c}, \mathrm{r}}\right)$, respectively, of the thermohydrogravidynamic processes in the internal rigid core $\tau_{\mathrm{c}, \mathrm{r}}$ and in the boundary region $\tau_{\mathrm{rf}}$ between the internal rigid core $\tau_{\mathrm{c}, \mathrm{r}}$ and the fluid core $\tau_{\mathrm{c}, \mathrm{f}}$ of the Earth) are formulated as follows $[8,15,23]$ :

$$
\Delta \mathrm{G}\left(\tau_{\mathrm{c}, \mathrm{r}}, \mathrm{t}^{*}\left(\tau_{\mathrm{c}, \mathrm{r}}\right)\right)=\max _{\mathrm{t}} \int_{\mathrm{t}_{0}}^{\mathrm{t}} \mathrm{dt} \mathrm{t}^{\prime} \iiint_{\tau_{\mathrm{c}, \mathrm{r}}} \frac{\partial \psi_{\text {comb }}}{\partial \mathrm{t}^{\prime}} \rho_{\mathrm{c}, \mathrm{r}} \mathrm{dV} \text { - local maximum for time moment } \mathrm{t}^{*}\left(\tau_{\mathrm{c}, \mathrm{r}}\right),
$$

And

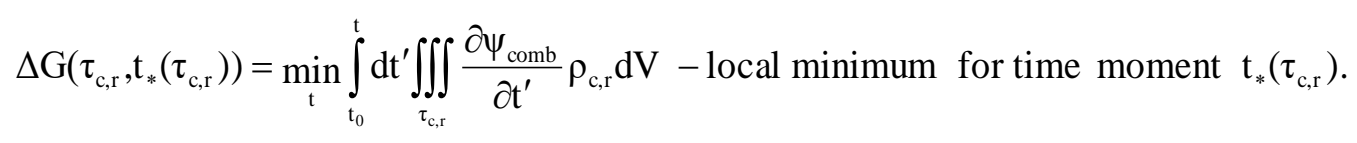

Here $\rho_{\mathrm{c}, \mathrm{r}}=12800 \mathrm{~kg} \cdot \mathrm{m}^{-3}$ [29] is the mass density of the internal rigid core $\tau_{\mathrm{c}, \mathrm{r}}$, $\partial \psi_{\text {comb }} / \partial \mathrm{t} \equiv \partial \psi_{\text {comb }}\left(\tau_{\mathrm{c}, \mathrm{r}}, \mathrm{t}\right) / \partial \mathrm{t}$ is the partial derivative (of the combined cosmic gravitational potential $\psi_{\text {comb }} \equiv \psi_{\text {comb }}\left(\tau_{\mathrm{c}, \mathrm{r}}, \mathrm{t}\right)$ in the internal rigid core $\tau_{\mathrm{c}, \mathrm{r}}$ of the Earth) approximated as follows $[8,15,23]$

$$
\psi_{\text {comb }}\left(\tau_{c, r}, t\right)=\psi_{3 \text { MOON }}\left(C_{3}, t\right)+\sum_{i=1, i \neq 3}^{9} \psi_{3 i}\left(C_{3}, t\right)+\sum_{j=5}^{8} \psi_{3 j}^{\mathrm{S}}\left(\mathrm{C}_{3}, \mathrm{t}\right)
$$

where $\psi_{3 \text { MoON }}\left(\mathrm{C}_{3}, \mathrm{t}\right)$ is the gravitational potential $[2,7,8,30]$ created by the Moon at the mass center $\mathrm{C}_{3}$ of the Earth, $\psi_{3 \mathrm{i}}\left(\mathrm{C}_{3}, \mathrm{t}\right)$ is the gravitational potential $[2,7,8,14,30]$ created by the planet $\tau_{\mathrm{i}}$ at the mass center $\mathrm{C}_{3}$ of the Earth, $\psi_{3 \mathrm{j}}^{\mathrm{s}}\left(\mathrm{C}_{3}, \mathrm{t}\right)$ is the gravitational potential [8, 15] created by the Sun (due to the gravitational interaction of the Sun with the outer large planet $\tau_{\mathrm{j}}$ ) at the mass center $\mathrm{C}_{3}$ of the Earth. The global prediction thermohydrogravidynamic principles (5) and (6) define the maximal and minimal combined cosmic integral energy gravitational influences ((5) and (6), respectively, for the time moments $\mathrm{t}=\mathrm{t}^{*}\left(\tau_{\mathrm{c}, \mathrm{r}}\right)$ and $\left.\mathrm{t}=\mathrm{t}_{*}\left(\tau_{\mathrm{c}, \mathrm{r}}\right)\right)$ on the considered internal rigid core $\tau_{c, r}$ (of the Earth) subjected to the combined cosmic integral energy gravitational influence of the planets of the Solar System, the Moon and the Sun (owing to the gravitational interaction of the Sun with the outer large planets).

\section{Findings}

To predict in advance (on 31 August, 2016 [31, 32]) the forthcoming ranges (since 1 September, 2016 [31, 32] and before 26 January, 2017 [32]) of the next active forthcoming intensifications of the global natural (seismotectonic, volcanic, climatic and magnetic) processes of the Earth, we used [31, 32] the established [8, 15] global prediction thermohydrogravidynamic principle (5) determining the maximal temporal intensification near the time moments $t=t^{*}\left(\tau_{c, r}\right)$ of the 
thermohydrogravidynamic processes $[8,15]$ in the internal rigid core $\tau_{c, r}$ and in the boundary region $\tau_{\mathrm{rf}}$ between the internal rigid core $\tau_{\mathrm{c}, \mathrm{r}}$ and the fluid core $\tau_{\mathrm{c}, \mathrm{f}}$ of the Earth. We presented [23] the confirmed [31, 32] validity of the established [8, 15] global prediction thermohydrogravidynamic principle (5) (of the thermohydrogravidynamic theory $[2-4,7,8,13$ $15,17,21,23,31,32]$ ) concerning the predicted (on 31 August, 2016 [31, 32]) strongest intensifications of the global natural (sesmotectonic and climatic) processes of the Earth in 2016 since 1 September, 2016 [31, 32] and before 26 January, 2017 [32].

Based on the established [8, 15] global prediction thermohydrogravidynamic principle (5) determining the maximal temporal intensification near the time moment $\mathrm{t}=\mathrm{t}^{*}\left(\tau_{\mathrm{c}, \mathrm{r}}\right)$ of the thermohydrogravidynamic processes $[8,15]$ in the internal rigid core $\tau_{c, r}$ and in the boundary region $\tau_{\mathrm{rf}}$ between the internal rigid core $\tau_{\mathrm{c}, \mathrm{r}}$ and the fluid core $\tau_{\mathrm{c}, \mathrm{f}}$ of the Earth, we predicted in advance (on 10 April, 2017 [33]) the forthcoming ranges of the next active forthcoming intensifications of the global natural (seismotectonic, volcanic, climatic and magnetic) processes of the Earth since 18 July, 2017 [23, 33] and before 26 February, 2018 [23, 33]. We used the global prediction thermohydrogravidynamic principle (5) to obtain (for the considered real planetary configurations of the Earth and the planets of the Solar System) the numerical time moment $\mathrm{t}^{*}\left(\tau_{\mathrm{c}, \mathrm{r}}, 2017\right)$ corresponding to the maximal (in 2017) combined planetary and solar integral energy gravitational influence (5) on the internal rigid core $\tau_{c, r}$ of the Earth. Based on the global prediction thermohydrogravidynamic principle (5) and considering the real planetary configurations of the Earth and the planets of the Solar System for 2017, we obtained (on 10 April, 2017 [33]) the numerical time moment (related with the maximal (in 2017) combined planetary and solar integral energy gravitational influence (5) on the internal rigid core $\tau_{c, r}$ of the Earth) $[23,33]$ :

$$
\mathrm{t}^{*}\left(\tau_{\mathrm{c}, \mathrm{r}}, 2017\right)=2017.85
$$

Which corresponds approximately to 7 November, 2017. Based on the global prediction thermohydrogravidynamic principle $(5)$ used for the range $(2004 \div 2016)$, we calculated [31, 32] the dates $\mathrm{t}^{*}\left(\tau_{\mathrm{c}, \mathrm{r}},(2004+\mathrm{m})\right) \quad(\mathrm{m}=0,1, \ldots, 12)$ corresponding to the different local maxima (5) of the combined planetary and solar integral energy gravitational influences (for the real planetary configurations during the range $(2004 \div 2016)$ ) on the Earth.

Considering the range $(2004 \div 2016)$ and analyzing the previous strongest earthquakes (occurred near the calculated dates $\left.\mathrm{t}^{*}\left(\tau_{\mathrm{c}, \mathrm{r}},(2004+\mathrm{m})\right), \mathrm{m}=0,1, \ldots, 12\right)$, we calculated (on 10 April, 2017 [33]) the following probabilities [23, 33]

$$
\begin{aligned}
& \operatorname{Pr}\left\{\mathrm{t}_{\mathrm{e}, \mathrm{max}, 2017} \in(5 \text { November } \div 9 \text { November, } 2017)\right\}=0.077, \\
& \operatorname{Pr}\left\{\mathrm{t}_{\mathrm{e}, \mathrm{max}, 2017} \in(4 \text { November } \div 10 \text { November, } 2017)\right\}=0.154, \\
& \operatorname{Pr}\left\{\mathrm{t}_{\mathrm{e}, \mathrm{max}, 2017} \in(3 \text { November } \div 11 \text { November, } 2017)\right\}=0.23, \\
& \operatorname{Pr}\left\{\mathrm{t}_{\mathrm{e}, \mathrm{max}, 2017} \in(29 \text { October } \div 17 \text { November, } 2017)\right\}=0.307,
\end{aligned}
$$


$\operatorname{Pr}\left\{\mathrm{t}_{\mathrm{e}, \max , 2017} \in(22\right.$ October $\div 23$ November, 2017) $\}=0.384$,

$\operatorname{Pr}\left\{\mathrm{t}_{\mathrm{e}, \mathrm{max}, 2017} \in(13\right.$ October $\div 1$ December, 2017) $\}=0.461$,

$\operatorname{Pr}\left\{\mathrm{t}_{\mathrm{e}, \max , 2017} \in(12\right.$ October $\div 2$ December, 2017) $\}=0.538$,

$\operatorname{Pr}\left\{\mathrm{t}_{\mathrm{e}, \text { max }, 2017} \in(6\right.$ October $\div 8$ December, 2017) $\}=0.692$,

$\operatorname{Pr}\left\{\mathrm{t}_{\mathrm{e} \text {,max } 2017-2018} \in(12\right.$ September, 2017 $\div 1$ January, 2018) $\}=0.769$,

$\operatorname{Pr}\left\{t_{e, \text { max }, 2017-2018} \in(1\right.$ August, 2017 $\div 12$ February, 2018) $\}=0.846$,

$\operatorname{Pr}\left\{\mathrm{t}_{\mathrm{e} \text {,max }, 2017-2018} \in(22 \mathrm{July}, 2017 \div 22\right.$ February, 2018) $\}=0.923$,

$\operatorname{Pr}\left\{\mathrm{t}_{\mathrm{e}, \text { max }, 2017-2018} \in(18 \mathrm{July}, 2017 \div 26\right.$ February, 2018) $\}=0.99$

of the forthcoming strongest earthquakes (and related [4, 7, 8, 13-15, 17, 25, 31, 32] strongest volcanic, climatic and magnetic processes in 2017 since 18 July, 2017 and before 26 February, 2018) near the numerical time moment $\mathrm{t}^{*}\left(\tau_{c, r}, 2017\right)=2017.85$ corresponding approximately to 7 November, 2017) during the calculated (on 10 April, 2017 [33]) following ranges [23, 33]:

(5 November $\div 9$ November, 2017),

(4 November $\div 10$ November, 2017),

(3 November $\div 11$ November, 2017),

(29 October $\div 17$ November, 2017),

(22 October $\div 23$ November, 2017),

(13 October $\div 1$ December, 2017),

(12 October $\div 2$ December, 2017),

(6 October $\div 8$ December, 2017),

(12 September, 2017 $\div 1$ January, 2018),

(1 August, 2017 $\div 12$ February, 2018),

(22 July, 2017 $\div 22$ February, 2018),

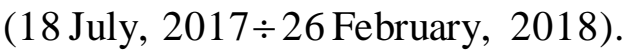

We concluded [23] that the dates $t_{e, \max , 2017}$ and $t_{e, \max , 2017-2018}$ of the forthcoming strongest earthquakes (and related $[4,7,8,13-15,17,25,31,32]$ strongest volcanic, climatic and magnetic processes of the Earth determined by the maximal (in 2017) combined planetary and solar integral energy gravitational influence (5) on the internal rigid core $\tau_{c, r}$ of the Earth near the numerical time moment $\mathrm{t}^{*}\left(\tau_{\mathrm{c}, \mathrm{r}}, 2017\right)=2017.85$ corresponding approximately to 7 November, 2017) will occur during the ranges (21), (22), (23), (24), (25), (26), (27), (28), (29), (30), (31) and (32) characterized by the probabilities (9), (10), (11), (12), (13), (14), (15), (16), (17), (18), (19) and (20), correspondingly.

To predict in advance (on 25 February, 2018) the forthcoming ranges of the next active forthcoming intensifications of the global natural (seismotectonic, volcanic, climatic and magnetic) processes of the Earth in 2018 during the first subrange since 26 February, 2018 and 
before 24 August, 2018, we use the established [8, 15, 23, 31, 32] global prediction thermohydrogravidynamic principle (6) determining the maximal temporal intensification near the time moment $\mathrm{t}=\mathrm{t}_{*}\left(\tau_{\mathrm{c}, \mathrm{r}}\right)$ of the thermohydrogravidynamic processes $[8,15]$ in the internal rigid core $\tau_{\mathrm{c}, \mathrm{r}}$ and in the boundary region $\tau_{\mathrm{rf}}$ between the internal rigid core $\tau_{\mathrm{c}, \mathrm{r}}$ and the fluid core $\tau_{\mathrm{c}, \mathrm{f}}$ of the Earth. We use the principle (6) to obtain (for the considered real planetary configurations of the Earth and the planets of the Solar System) the numerical time moment $\mathrm{t}_{*}\left(\tau_{\mathrm{c}, \mathrm{r}}, 2018\right)$ corresponding to the minimal (in 2018) combined planetary and solar integral energy gravitational influence (6) on the internal rigid core $\tau_{c, r}$ of the Earth. Based on the global prediction thermohydrogravidynamic principle (6) and considering the real planetary configurations of the Earth and the planets of the Solar System for 2018, we obtained (on 25 February, 2018) the numerical time moment (related with the minimal (in 2018) combined planetary and solar integral energy gravitational influence (6) on the internal rigid core $\tau_{c, r}$ of the Earth):

$$
\mathrm{t}_{*}\left(\tau_{\mathrm{c}, \mathrm{r}}, 2018\right)=2018.4
$$

Which corresponds approximately to 26 May, 2018. Based on the global prediction thermohydrogravidynamic principle (6) used for the range $(2004 \div 2017)$, we calculated [34] the dates $\mathrm{t}_{*}\left(\tau_{\mathrm{c}, \mathrm{r}},(2004+\mathrm{m})\right)(\mathrm{m}=0,1, \ldots, 13)$ corresponding to the different local minimums $(6)$ of the combined planetary and solar integral energy gravitational influences (for the real planetary configurations during the range $(2004 \div 2017)$ ) on the Earth.

Considering the range $(2004 \div 2017)$ and analyzing the previous strongest earthquakes (occurred near the calculated dates $\mathrm{t}_{*}\left(\tau_{\mathrm{c}, \mathrm{r}},(2004+\mathrm{m})\right), \mathrm{m}=0,1, \ldots, 13$ [34]), we calculate (on 25 February, 2018) the following probabilities

$$
\begin{aligned}
& \operatorname{Pr}\left\{\mathrm{t}_{\mathrm{e}, \mathrm{min}, 2018} \in(26.34 \text { February } \div 1 \text { March, 2018) }\}=0.1333\right. \text {, } \\
& \operatorname{Pr}\left\{\mathrm{t}_{\mathrm{e}, \mathrm{min}, 2018} \in(26.34 \text { February } \div 27 \text { March, 2018) }\}=0.2\right. \text {, } \\
& \operatorname{Pr}\left\{\mathrm{t}_{\mathrm{e}, \min , 2018} \in(26.34 \text { February } \div 1 \text { April, 2018) }\}=0.2666\right. \text {, } \\
& \operatorname{Pr}\left\{\mathrm{t}_{\mathrm{e}, \min , 2018} \in(26.34 \text { February } \div 6 \text { April, 2018) }\}=0.3333\right. \text {, } \\
& \operatorname{Pr}\left\{\mathrm{t}_{\mathrm{e}, \min , 2018} \in(26.34 \text { February } \div 10 \text { May, 2018) }\}=0.4\right. \text {, } \\
& \operatorname{Pr}\left\{\mathrm{t}_{\mathrm{e}, \mathrm{min}, 2018} \in(26.34 \text { February } \div 23 \text { May, 2018) }\}=0.4666\right. \text {, } \\
& \operatorname{Pr}\left\{\mathrm{t}_{\mathrm{e}, \mathrm{min}, 2018} \in(24 \text { May } \div 30 \text { May, 2018) }\}=0.0666\right. \text {, } \\
& \operatorname{Pr}\left\{\mathrm{t}_{\mathrm{e}, \min , 2018} \in(24 \text { May } \div 4 \text { June, 2018) }\}=0.1333\right. \text {, } \\
& \operatorname{Pr}\left\{\mathrm{t}_{\mathrm{e}, \mathrm{min}, 2018} \in(24 \text { May } \div 23 \text { June, 2018) }\}=0.2\right. \text {, } \\
& \operatorname{Pr}\left\{\mathrm{t}_{\mathrm{e}, \mathrm{min}, 2018} \in(24 \text { May } \div 2 \text { July, 2018) }\}=0.2666\right. \text {, } \\
& \operatorname{Pr}\left\{\mathrm{t}_{\mathrm{e}, \min , 2018} \in(24 \text { May } \div 12 \text { July, 2018) }\}=0.3333\right. \text {, } \\
& \operatorname{Pr}\left\{\mathrm{t}_{\mathrm{e}, \mathrm{min}, 2018} \in(24 \text { May } \div 18 \mathrm{July}, 2018)\right\}=0.4 \text {, }
\end{aligned}
$$




$$
\begin{aligned}
& \operatorname{Pr}\left\{\mathrm{t}_{\mathrm{e}, \min , 2018} \in(24 \text { May } \div 20 \text { August, } 2018)\right\}=0.4666, \\
& \operatorname{Pr}\left\{\mathrm{t}_{\mathrm{e}, \min , 2018} \in(24 \text { May } \div 24 \text { August, } 2018)\right\}=0.5333
\end{aligned}
$$

of the forthcoming strongest earthquakes (and related [4, 7, 8, 13-15, 17, 25, 31, 32] strongest volcanic, climatic and magnetic processes in 2018 since 26.34 February $(8.14 \mathrm{hr}$ since 26 February, 2018) and before 24 August, 2018) near the numerical time moment $\mathrm{t}_{*}\left(\tau_{\mathrm{c}, \mathrm{r}}, 2018\right)=2018.4$ corresponding approximately to 26 May, 2018) during the calculated (on 25 February, 2018) following ranges:

$$
\begin{aligned}
& \text { (26.34 February } \div 1 \text { March, 2018), } \\
& (26.34 \text { February } \div 27 \text { March, 2018), } \\
& (26.34 \text { February } \div 1 \text { April, 2018), } \\
& (26.34 \text { February } \div 6 \text { April, 2018), } \\
& (26.34 \text { February } \div 10 \text { May, 2018), } \\
& (26.34 \text { February } \div 23 \text { May, 2018), } \\
& (24 \text { May } \div 30 \text { May, 2018), } \\
& \text { (24 May } \div 4 \text { June, 2018), } \\
& (24 \text { May } \div 23 \text { June, 2018), } \\
& \text { (24 May } \div 2 \text { July, 2018), } \\
& \text { (24 May } \div 12 \text { July, 2018), } \\
& \text { (24 May } \div 18 \text { July, 2018), } \\
& \text { (24 May } \div 20 \text { August, 2018), } \\
& \text { (24 May } \div 24 \text { August, 2018). }
\end{aligned}
$$

It means that the dates $t_{\mathrm{e}, \min x, 2018}$ of the forthcoming strongest earthquakes (and related $[4,7,8$, 13-15, 17, 25, 31, 32] strongest volcanic, climatic and magnetic processes of the Earth determined by the minimal (in 2018) combined planetary and solar integral energy gravitational influence (6) on the internal rigid core $\tau_{\mathrm{c}, \mathrm{r}}$ of the Earth near the numerical time moment $\mathrm{t}_{*}\left(\tau_{\mathrm{c}, \mathrm{r}}, 2018\right)=2018.4$ corresponding approximately to 26 May, 2018) will occur during the ranges (48), (49), (50), (51), (52), (53), (54), (55), (56), (57), (58), (59), (60) and (61) characterized by the probabilities (34), (35), (36), (37), (38), (39), (40), (41), (42), (43), (44), (45), (46) and (47), correspondingly.

These ranges (48) - (61) and the corresponding probabilities (34) - (47) were founded exceptionally (by eliminating the analysis of the strongest global climatic activity of the Earth during the range $(2004 \div 2017)$ ) based on the combined analysis of the dates of the previous strongest earthquakes occurred during the range $(2004 \div 2017)$ near the calculated dates $\mathrm{t}_{*}\left(\tau_{\mathrm{c}, \mathrm{r}},(2004+\mathrm{m})\right)(\mathrm{m}=0,1, \ldots, 13)$ corresponding to the different local minimums $(6)$ of the combined planetary and solar integral energy gravitational influences (related with the real 
planetary configurations during the range $(2004 \div 2017))$ on the internal rigid core $\tau_{\mathrm{c}, \mathrm{r}}$ of the Earth $\tau_{3}$ and on the Earth as a whole.

\section{Discussions}

We discussed [23] the confirmed validity of the prediction [31, 32] of the thermohydrogravidynamic theory (based on the established [8, 15] global prediction thermohydrogravidynamic principle (5)) concerning the strongest intensifications of the global natural processes of the Earth since 1 September, 2016 [31, 32] and before 26 January, 2017 [32] determined by the maximal (in 2016) combined planetary (of the Mercury, Venus, Mars and Jupiter) and solar (due to the gravitational interactions of the Sun with the Jupiter, Saturn, Uranus and Neptune) integral energy gravitational influence (5) on the internal rigid core $\tau_{\mathrm{c}, \mathrm{r}}$ of the Earth near the numerical time moment $t^{*}\left(\tau_{c, r}, 2016\right)=2016.7666$ corresponding approximately to 6 October, 2016.

We discussed [34] the confirmed validity of the thermohydrogravidynamic theory concerning the first subrange of the strongest intensifications of the global natural processes of the Earth in 2017 since 10 April, 2017 and before 6 August, 2017 [33, 34] determined by the minimal (in 2017) combined planetary (of the Mercury, Venus, Mars and Jupiter) and solar (due to the gravitational interactions of the Sun with the Jupiter, Saturn, Uranus and Neptune) integral energy gravitational influence (6) on the internal rigid core $\tau_{\mathrm{c}, \mathrm{r}}$ of the Earth near the numerical time moment $t_{*}\left(\tau_{c, r}, 2017\right)=2017.3$ corresponding approximately to 20 April, 2017.

We discussed (on 31 August, 2017 during the date of the second submission of the corrected article [23] for publication to the International Journal of Research - GRANTHAALAYAH) the confirmed validity of the prediction (made on 10 April, 2017 [33, 34]) of the thermohydrogravidynamic theory (based on the established [8, 15] global prediction thermohydrogravidynamic principle (5)) concerning the strongest intensifications of the global natural (seismotectonic, volcanic and climatic) processes of the Earth determined by the maximal (in 2017) combined planetary (of the Mercury, Venus, Mars and Jupiter) and solar (due to the gravitational interactions of the Sun with the Jupiter, Saturn, Uranus and Neptune) integral energy gravitational influence (5) on the internal rigid core $\tau_{\mathrm{c}, \mathrm{r}}$ of the Earth near the numerical time moment $\mathrm{t}^{*}\left(\tau_{\mathrm{c}, \mathrm{r}}, 2017\right)=2017.85$ corresponding approximately to 7 November, 2017 . Considering (on 31 August, 2017) the significant earthquakes (according to the U.S. Geological Survey) in 2017 before 31 August, 2017, we pointed out [23] the unquestionable fact that the date (17 July, 2017, 23:34:13 UTC) of the strongest 7.8-magnitude (strongest in 2017 before 31 August, 2017 according to the U.S. Geological Survey) earthquake (which struck Russia's Kamchatka Peninsula $198 \mathrm{~km}$ ESE of Nikol'skoye according to the U.S. Geological Survey) belongs practically (with the error of 26 minutes) to the predicted (on 10 April, 2017 [33]) range (32) characterized by the probability (20). However, this strongest 7.8-magnitude (strongest in 2017 before 31 August, 2017 according to the U.S. Geological Survey) earthquake (which struck Russia's Kamchatka Peninsula) belongs really to the first subrange of the strongest (in 2017) intensifications of the global natural processes of the Earth since 10 April, 2017 and before 
6 August, 2017 [33, 34] since this strongest 7.8-magnitude earthquake was realized on the date $\mathrm{t}_{\mathrm{e}} \approx 18$ July, $2017=2017.46594$, which is near 60.61 days after the date $\mathrm{t}_{*}\left(\tau_{\mathrm{c}, \mathrm{r}}, 2017\right)=2017.3$ $[33,34]$ (corresponding to the local minimal (in 2017) combined planetary and solar integral energy gravitational influence (6) on the internal rigid core $\tau_{\mathrm{c}, \mathrm{r}}$ of the Earth), but the date $\mathrm{t}_{\mathrm{e}} \approx$ 18 July, $2017=2017.46594$ is near 140.27 days (which is larger than 60.61 days) before the date $\mathrm{t}^{*}\left(\tau_{\mathrm{c}, \mathrm{r}}, 2017\right)=2017.85[33,34]$ (corresponding to the local maximal (in 2017) combined planetary and solar integral energy gravitational influence (5) on the internal rigid core $\tau_{c, r}$ of the Earth).

We pointed out [23] the unquestionable fact ([35] published on July 20, 2017) that "on Wednesday, the University of Utah Seismograph Stations (UUSS) had recorded 1,284 events, the largest being magnitude 4.4" [35]. We stated [23] that the period of the Yellowstone supervolcano intensification (on Wednesday, July 19, 2017 [35]) belongs to the predicted (on 10 April, 2017 [33, 34]) range (32) characterized by the probability (20). However, we see (based on the analogous arguments) that the Yellowstone supervolcano intensification (on Wednesday, July 19, 2017 [35]) belongs really to the predicted (on 10 April, 2017 [33, 34]) first subrange of the strongest intensifications of the global natural processes of the Earth in 2017 since 10 April, 2017 and before 6 August, 2017 [33, 34].

We pointed out [23] the unquestionable fact ([36] published on July 31, 2017) that "the flooding has paralysed Gujarat" [36]. We stated [23] that the period of the Indian severe monsoon floods (especially in Gujarat [36]) belongs to the predicted (on 10 April, 2017 [33, 34]) range (31) characterized by the probability (19). However, we see (based on the analogous arguments) that the period of the Indian severe monsoon floods (especially in Gujarat [36]) belongs really to the predicted (on 10 April, 2017 [33, 34]) first subrange of the strongest intensifications of the global natural processes of the Earth in 2017 since 10 April, 2017 and before 6 August, 2017 [33, 34].

We pointed out [23] the unquestionable fact ([37] published on August 8, 2017) that "typhoon Noru dumped heavy rain on Japan Tuesday as it moved back out to sea, causing flooding and property damage while the number of injured reportedly rose to 51" [37]. We see that the period of the typhoon Noru belongs really to the predicted (on 10 April, 2017 [33, 34]) range (30) characterized by the probability (18).

We pointed out [23] the unquestionable fact ([38] published on August 22, 2017) that "more than 800 people have been killed and 24 million affected following widespread floods across south Asia" [38]. We see that the period of the widespread floods across south Asia belongs really to the predicted (on 10 April, 2017 [33, 34]) range (30) characterized by the probability (18).

We pointed out [23] the unquestionable fact ([39] published on August 27, 2017) that "damaging hurricane Harvey settles in over southeast Texas" [39]. We see that the period of the damaging hurricane Harvey belongs really to the predicted (on 10 April, 2017 [33, 34]) range (30) characterized by the probability (18).

Thus, owing to the intersection during the range since 18 July, 2017 and before 6 August, 2017 (of the predicted (on 10 April, 2017 [33, 34]) first subrange of the strongest intensifications of 
the global natural processes of the Earth since 10 April, 2017 and before 6 August, 2017 [33, 34] and the second subrange of the strongest intensifications of the global natural processes of the Earth since 18 July, 2017 and before 26 February, 2018 [23, 33]), we see that it is necessary to consider correctly the second subrange of the strongest intensifications of the global natural processes of the Earth since 6 August, 2017 (instead of 18 July, 2017 [23, 33]) and before 26 February, 2018 [23, 33].

To demonstrate the confirmed validity of the thermohydrogravidynamic theory concerning the predicted [23, 33] second subrange of the strongest intensifications of the global natural processes of the Earth since 18 July, 2017 (really since 6 August, 2017 as pointed out above) and before 26 February, 2018, we present the Table 1 containing the analysis (finished on February 27, 2018) for $2017(\mathrm{~m}=13)$ of the previous strongest (since 6 August, 2017 and before February 26, 2018 according to the U.S. Geological Survey) earthquakes (characterized by magnitudes $M \geq 6.9$ ) of the Earth occurred on dates $t_{e}$ near the calculated [23, 33] date $\mathrm{t}^{*}\left(\tau_{\mathrm{c}, \mathrm{r}}, 2017\right)=2017.85$ (related with the maximal (in 2017) combined planetary and solar integral energy gravitational influence (5) on the internal rigid core $\tau_{c, r}$ of the Earth) during the range (since 6 August, 2017 and before 26 February, 2018 [23, 33]) of the strongest intensifications of the global seismotectonic, volcanic and climatic processes of the Earth.

We use the following simple approximate relations (for date $\mathrm{x} \in(1,2, \ldots, 31)$ and for year $\mathrm{j} \in(2017,2018)$ :

$$
\begin{aligned}
& \text { February } x, j=j+1 / 12+x / 365.25, \\
& \text { January } x, j=j+x / 365.25, \\
& \text { November } x, j=j+10 / 12+x / 365.25, \\
& \text { September } x, j=j+8 / 12+x / 365.25,
\end{aligned}
$$

for prompt calculation of the dates $t_{e}$ (given in $y r$ in the considered Table 1 ) for the considered significant (according to the U.S. Geological Survey) earthquakes and for prompt calculation of the corresponding differences $\Delta=\left|\mathrm{t}_{\mathrm{e}}-\mathrm{t}^{*}\left(\tau_{\mathrm{c}, \mathrm{r}}, 2017\right)\right|$ (given in days with the error of \pm 1.5 day in the presented Table 1 for $\mathrm{j}=2017$ and $\mathrm{j}=2018$ ).

We see (based on the Table 1) the first unquestionable fact that the powerful 8.2-magnitude (strongest since 6 August, 2017 and before 26 February, 2018 [23, 33] according to the U.S. Geological Survey) earthquake (occurred on September 8, 2017 about $101 \mathrm{~km}$ SSW of Tres Picos, Mexico according to the U.S. Geological Survey) was realized near 58.96 days before the date $t^{*}\left(\tau_{c, r}, 2017\right)=2017.85$. We see (based on the Table 1$)$ the second unquestionable fact that the powerful 7.9-magnitude (second strongest since 6 August, 2017 and before 26 February, 2018 [23, 33] according to the U.S. Geological Survey) earthquake (occurred on January 23, 2018 about $280 \mathrm{~km}$ SE of Kodiak, Alaska according to the U.S. Geological Survey) was realized near 77.78 days after the date $\mathrm{t}^{*}\left(\tau_{\mathrm{c}, \mathrm{r}}, 2017\right)=2017.85$. This facts demonstrate the reasonable applicability of the global prediction thermohydrogravidynamic principle (5) for explanation of 
the global seismotectonic activity of the Earth in 2017 and for explanation of the strongest (in 2017) seismotectonic activity in Mexico for 2017 and in USA for 2018.

We see (based on the Table 1) the third unquestionable fact that the strongest 8.2-magnitude earthquake (occurred on September 8, 2017 about $101 \mathrm{~km} \mathrm{SSW}$ of Tres Picos, Mexico) and the 7.9-magnitude earthquake (occurred on January 23, 2018 about $280 \mathrm{~km}$ SE of Kodiak, Alaska) were realized during the predicted (on 10 April, 2017 [23, 33]) range (30) of the probable strongest (in 2017 and 2018) intensifications (characterized by the corresponding probability $\operatorname{Pr}=0.846$ (given by (18)) of the global seismotectonic and climatic processes of the Earth.

Table 1: The analysis for $2017(\mathrm{~m}=13)$ of the previous strongest (since 6 August, 2017 and before February 26, 2018 according to the U.S. Geological Survey) earthquakes (characterized

by magnitudes $M \geq 6.9$ ) of the Earth occurred on dates $t_{e}$ near the calculated [23, 33] date

$\mathrm{t}^{*}\left(\tau_{\mathrm{c}, \mathrm{r}}, 2017\right)=2017.85$ (related with the maximal (in 2017) combined planetary and solar integral energy gravitational influence (5) on the internal rigid core $\tau_{\mathrm{c}, \mathrm{r}}$ of the Earth) during the range (since 6 August, 2017 and before 26 February, 2018 [23, 33]) of the strongest intensification of the global seismotectonic processes

\begin{tabular}{|c|c|c|c|}
\hline Magnitude M, Region & $\begin{array}{c}\text { Date } \mathrm{t}_{\mathrm{e}} \text { of } \\
\text { earthquake, in } \mathrm{yr}\end{array}$ & $\begin{array}{c}\text { Date } \\
\mathrm{t}^{*}\left(\tau_{\mathrm{c}, \mathrm{r}}, 2017\right) \\
=2017.85, \text { in } \mathrm{yr}\end{array}$ & $\begin{array}{c}\Delta=\left|\mathrm{t}_{\mathrm{e}}-\mathrm{t}^{*}\left(\tau_{\mathrm{c}, \mathrm{r}}, 2017\right)\right|, \\
\text { in days }\end{array}$ \\
\hline $\begin{array}{l}\mathrm{M}=7.5,89 \mathrm{~km} \mathrm{SSW} \text { of } \\
\text { Porgera, Papua New } \\
\text { Guinea }\end{array}$ & $\begin{array}{l}\text { February } 25,2018 \\
=2018.151779\end{array}$ & 2017.85 & $\begin{array}{l}110.22 \text { days after the date } \\
\mathrm{t}^{*}\left(\tau_{\mathrm{c}, \mathrm{r}}, 2017\right)\end{array}$ \\
\hline $\begin{array}{l}\mathrm{M}=7.2,37 \mathrm{~km} \mathrm{NE} \text { of } \\
\text { Pinotepa de Don Luis, } \\
\text { Mexico }\end{array}$ & $\begin{array}{l}\text { February } 16,2018 \\
=2018.127138\end{array}$ & 2017.85 & $\begin{array}{l}101.22 \text { days after the date } \\
\mathrm{t}^{*}\left(\tau_{\mathrm{c}, \mathrm{r}}, 2017\right)\end{array}$ \\
\hline $\begin{array}{l}\mathrm{M}=7.9,280 \mathrm{~km} \text { SE of } \\
\text { Kodiak, Alaska }\end{array}$ & $\begin{array}{l}\text { January } 23,2018 \\
=2018.06297\end{array}$ & 2017.85 & $\begin{array}{l}77.78 \text { days after the date } \\
\mathrm{t}^{*}\left(\tau_{\mathrm{c}, \mathrm{r}}, 2017\right)\end{array}$ \\
\hline $\begin{array}{l}\mathrm{M}=7.1,37 \mathrm{~km} \mathrm{SSW} \\
\text { of Acari, Peru }\end{array}$ & $\begin{array}{l}\text { January } 14,2018 \\
=2018.038329\end{array}$ & 2017.85 & $\begin{array}{l}68.78 \text { days after the date } \\
\mathrm{t}^{*}\left(\tau_{\mathrm{c}, \mathrm{r}}, 2017\right)\end{array}$ \\
\hline $\begin{array}{l}\mathrm{M}=7.5,44 \mathrm{~km} \mathrm{E} \text { of } \\
\text { Great Swan Island, } \\
\text { Honduras }\end{array}$ & $\begin{array}{l}\text { January } 10,2018 \\
=2018.027378\end{array}$ & 2017.85 & $\begin{array}{l}64.78 \text { days after the date } \\
\mathrm{t}^{*}\left(\tau_{\mathrm{c}, \mathrm{r}}, 2017\right)\end{array}$ \\
\hline $\begin{array}{l}\mathrm{M}=7.0,85 \mathrm{~km} \text { ENE } \\
\text { of Tadine, New } \\
\text { Caledonia }\end{array}$ & $\begin{array}{l}\text { November 19, } \\
2017 \\
=2017.885352\end{array}$ & 2017.85 & $\begin{array}{l}\text { 12.91 days after the date } \\
\mathrm{t}^{*}\left(\tau_{\mathrm{c}, \mathrm{r}}, 2017\right)\end{array}$ \\
\hline $\begin{array}{l}\mathrm{M}=7.3,29 \mathrm{~km} \mathrm{~S} \text { of } \\
\text { Halabjah, Iraq }\end{array}$ & $\begin{array}{l}\text { November } 12, \\
2017 \\
=2017.866187\end{array}$ & 2017.85 & $\begin{array}{l}\text { 5.91 days after the date } \\
\mathrm{t}^{*}\left(\tau_{\mathrm{c}, \mathrm{r}}, 2017\right)\end{array}$ \\
\hline $\begin{array}{l}\mathrm{M}=7.1,1 \mathrm{~km} \mathrm{E} \text { of } \\
\text { Ayutla, Mexico }\end{array}$ & $\begin{array}{l}\text { September } 19, \\
2017 \\
=2017.718685 \\
\end{array}$ & 2017.85 & $\begin{array}{l}\text { 47.96 days before the date } \\
\mathrm{t}^{*}\left(\tau_{\mathrm{c}, \mathrm{r}}, 2017\right)\end{array}$ \\
\hline
\end{tabular}




\begin{tabular}{|l|l|l|l|}
\hline $\begin{array}{l}\mathrm{M}=8.2,101 \mathrm{~km} \mathrm{SSW} \\
\text { of Tres Picos, Mexico }\end{array}$ & $\begin{array}{l}\text { September 8, } \\
2017 \\
=2017.688569\end{array}$ & 2017.85 & $\begin{array}{l}58.96 \text { days before the date } \\
\mathrm{t}^{*}\left(\tau_{c, \mathrm{r}}, 2017\right)\end{array}$ \\
\hline
\end{tabular}

This fact demonstrates the reasonable applicability of the global prediction thermohydrogravidynamic principle (5) for prediction [23,33] of the strongest (in 2017 and 2018) seismotectonic activity of the Earth. This fact confirms the cosmic energy gravitational genesis [33] of the strongest (in 2017 and 2018) earthquakes occurred (in Mexico and USA) near the calculated (on 10 April, 2017 [23, 33]) date $\mathrm{t}^{*}\left(\tau_{c, \mathrm{r}}, 2017\right)=2017.85$ (corresponding approximately to 7 November, 2017) related with the maximal (in 2017) combined planetary and solar integral energy gravitational influence (5) on the internal rigid core $\tau_{c, r}$ of the Earth.

\section{Conclusions}

We have presented in Section 2 (Methodology) the established [2-4, 7, 8, 13-15, 17, 21, 23, 25, 30-34] generalized formulation (1) of the first law of thermodynamics and the established [8, 15, 23, 31-34] global prediction thermohydrogravidynamic principles (5) and (6) (of the cosmic seismology $[8,15])$ determining the maximal temporal intensifications of the global and regional natural (seismotectonic, volcanic, climatic and magnetic) processes of the Earth. The generalization (1) of the first law of thermodynamics [2-4, 7, 8, 13-15, 17, 21, 23, 25, 30-34] is founded for the individual finite continuum region $\tau$ (considered in the Galilean frame of reference) subjected to the cosmic and terrestrial non-stationary Newtonian gravitational field and non-potential terrestrial stress forces characterized by the symmetric stress tensor $\mathbf{T}$ [22]. The established $[8,15,23,31-34]$ global prediction thermohydrogravidynamic principles (5) and (6) (determining (in the frame of the cosmic seismology $[8,15]$ ) the maximal temporal intensifications of the global natural (seismotectonic, volcanic, climatic and magnetic) processes of the Earth) are founded for the considered internal rigid core $\tau_{c, r}$ of the Earth subjected to the combined integral energy gravitational influence of the planets (Mercury, Venus, Mars and Jupiter), the Moon and the Sun due to the gravitational interactions of the Sun with Jupiter Saturn, Uranus and Neptune.

We have considered in Section 3 (Findings) the presented (on 21 August, 2017 [23]) prediction (made on 10 April, 2017 [33]) based on the global prediction thermohydrogravidynamic principle (5) concerning the strongest intensifications (in 2017 and 2018) of the global natural (seismotectonic, volcanic, climatic and magnetic) processes of the Earth determined by the maximal (in 2017) combined planetary and solar integral energy gravitational influence (near the time moment $\mathrm{t}^{*}\left(\tau_{\mathrm{c}, \mathrm{r}}, 2017\right)=2017.85$, which corresponds approximately to 7 November, 2017) on the internal rigid core $\tau_{c, r}$ of the Earth. We have considered in Section 3 (Findings) the founded (on 10 April, 2017 [33]) ranges (21) - (32) of the dates $t_{e, \text { max,2017 }}$ and $t_{e, \text { max,2017-2018 }}$ of the predicted strongest earthquakes (and related [4, 7, 8, 13-15, 17, 25, 31, 32] strongest volcanic, climatic and magnetic processes of the Earth determined by the maximal (in 2017) combined planetary and solar integral energy gravitational influence (5) on the internal rigid core $\tau_{c, r}$ of the Earth near the numerical time moment $\mathrm{t}^{*}\left(\tau_{c, r}, 2017\right)=2017.85$ corresponding approximately to 
7 November, 2017) characterized by the probabilities (9) - (20), correspondingly. Owing to the intersection from 18 July, 2017 to 6 August, 2017 (of the predicted (on 10 April, 2017 [33, 34]) first subrange of the strongest intensifications of the global natural processes of the Earth in 2017 since 10 April, 2017 and before 6 August, 2017 [33, 34] and the second subrange of the strongest intensifications of the global natural processes of the Earth since 18 July, 2017 and before 26 February, 2018 [23, 33]), we have shown (on 26 February, 2018) in Section 4 (Discussions) that it is reasonable to consider correctly the second subrange of the strongest intensifications of the global natural processes of the Earth since 6 August, 2017 and before 26 February, 2018 [23, 33]. We have presented (on 26 February, 2018) in Section 4 (Discussions) the total confirmed validity (including the considered confirmations [23]) of the prognostication [23, 33] based on the global prediction thermohydrogravidynamic principle (5) (of the thermohydrogravidynamic theory $[2-4,7,8,13-15,17,21,23,25,30-34])$ concerning the strongest intensifications of the global natural (seismotectonic and climatic) processes of the Earth since 6 August, 2017 and before 26 February, 2018 [23, 33].

Considering (on 26 February, 2018) the significant earthquakes (according to the U.S. Geological Survey) in 2017, we have shown that the date (17 July, 2017, 23:34:13 UTC) of the strongest 7.8-magnitude (strongest in 2017 before 31 August, 2017 according to the U.S. Geological Survey [23]) earthquake (which struck Russia's Kamchatka Peninsula) belongs really to the first subrange of the strongest intensifications of the global natural processes of the Earth in 2017 since 10 April, 2017 and before 6 August, 2017 [33, 34]. Considering (on 26 February, 2018) the unquestionable fact ([35] published on July 20, 2017) that "on Wednesday, the University of Utah Seismograph Stations (UUSS) had recorded 1,284 events, the largest being magnitude 4.4" [35], we have shown that the Yellowstone supervolcano intensification (on Wednesday, July 19, 2017 [35]) belongs really to the predicted (on 10 April, 2017 [33, 34]) first subrange of the strongest intensifications of the global natural processes of the Earth in 2017 since 10 April, 2017 and before 6 August, 2017 [33, 34]. Considering (on 26 February, 2018) the unquestionable fact ([36] published on July 31, 2017) that "the flooding has paralysed Gujarat" [36], we have shown that the period of the Indian severe monsoon floods (especially in Gujarat [36]) belongs really to the predicted (on 10 April, 2017 [33, 34]) first subrange of the strongest intensifications of the global natural processes of the Earth in 2017 since 10 April, 2017 and before 6 August, 2017 [33, 34]. Considering (on 26 February, 2018) the unquestionable fact ([37] published on August 8, 2017) that "typhoon Noru dumped heavy rain on Japan Tuesday as it moved back out to sea, causing flooding and property damage while the number of injured reportedly rose to 51" [37], we have shown that the period of the typhoon Noru belongs really to the predicted (on 10 April, 2017 [33, 34]) range (30) characterized by the probability (18). Considering (on 26 February, 2018) the unquestionable fact ([38] published on August 22, 2017) that "more than 800 people have been killed and 24 million affected following widespread floods across south Asia" [38], we have shown that the period of the widespread floods across south Asia belongs really to the predicted (on 10 April, 2017 [33, 34]) range (30) characterized by the probability (18). Considering (on 26 February, 2018) the unquestionable fact ([39] published on August 27, 2017) that "damaging hurricane Harvey settles in over southeast Texas" [39], we have shown that the period of the damaging hurricane Harvey belongs really to the predicted (on 10 April, 2017 [33, 34]) range (30) characterized by the probability (18). The analyzed (considered previously [23]) facts confirm the validity of the established [8, 15] global prediction thermohydrogravidynamic principles (5) and (6) (of the thermohydrogravidynamic 
theory $[2-4,7,8,13-15,17,21,23,25,30-34]$ ) concerning the first (since 10 April, 2017 and before 6 August, 2017 [33, 34]) and the second (since 6 August, 2017 (instead of 18 July, 2017 [23, 33]) and before 26 February, 2018 [23, 33]) subranges of the strongest (in 2017 and 2018) intensifications of the global natural (seismotectonic, volcanic and climatic) processes of the Earth since 10 April, 2017 [33, 34] and before 26 February, 2018 [23, 33].

Based on the Table 1, we have demonstrated (on 26 February, 2018) the additional first unquestionable fact that the powerful 8.2-magnitude (strongest since 6 August, 2017 and before 26 February, 2018 [23, 33] according to the U.S. Geological Survey) earthquake (occurred on September 8, 2017 about $101 \mathrm{~km} \mathrm{SSW}$ of Tres Picos, Mexico according to the U.S. Geological Survey) was realized near 58.96 days before the date $\mathrm{t}^{*}\left(\tau_{\mathrm{c}, \mathrm{r}}, 2017\right)=2017.85([23,33]$ related with the maximal (in 2017) combined planetary and solar integral energy gravitational influence (5) on the internal rigid core $\tau_{\mathrm{c}, \mathrm{r}}$ of the Earth) confirming the reasonable applicability of the global prediction thermohydrogravidynamic principle (5) for explanation of the global seismotectonic activity of the Earth in 2017 and for explanation of the strongest (in 2017) seismotectonic activity in Mexico for 2017. Based on the Table 1, we have demonstrated (on 26 February, 2018) the additional second unquestionable fact that the powerful 7.9-magnitude (second strongest since 6 August, 2017 and before 26 February, 2018 [23, 33] according to the U.S. Geological Survey) earthquake (occurred on January 23, 2018 about $280 \mathrm{~km}$ SE of Kodiak, Alaska according to the U.S. Geological Survey) was realized near 77.78 days after the date $\mathrm{t}^{*}\left(\tau_{\mathrm{c}, \mathrm{r}}, 2017\right)=2017.85[23,33]$ confirming the reasonable applicability of the global prediction thermohydrogravidynamic principle (5) for explanation of the global seismotectonic activity of the Earth in 2018 and for explanation of the strongest (in 2018 before 26 February, 2018) seismotectonic activity in USA for 2018.

Based on the Table 1, we have demonstrated (on 26 February, 2018) the additional third unquestionable fact that the strongest 8.2-magnitude earthquake (occurred on September 8, 2017 about $101 \mathrm{~km} \mathrm{SSW}$ of Tres Picos, Mexico) and the 7.9-magnitude (occurred on January 23, 2018 about $280 \mathrm{~km}$ SE of Kodiak, Alaska) were realized during the predicted (on 10 April, 2017 $[23,33]$ ) range (30) of the probable strongest (in 2017 and 2018) intensifications (characterized by the corresponding probability $\operatorname{Pr}=0.846$ (given by (18)) of the global seismotectonic and climatic processes of the Earth confirming the reasonable applicability of the global prediction thermohydrogravidynamic principle (5) for prediction [23, 33] of the strongest (in 2017 and 2018) seismotectonic activity of the Earth (especially, in Mexico for 2017 and in USA for 2018). Based on the global prediction thermohydrogravidynamic principle (6) and analyzing the range $(2004 \div 2017)$ of the previous strongest earthquakes (occurred near the calculated dates $\mathrm{t}_{*}\left(\tau_{\mathrm{c}, \mathrm{r}},(2004+\mathrm{m})\right), \mathrm{m}=0,1, \ldots, 13$ [34]), we have calculated (on 25 February, 2018) the ranges (48), (49), (50), (51), (52), (53), (54), (55), (56), (57), (58), (59), (60) and (61) (characterized by the probabilities (34), (35), (36), (37), (38), (39), (40), (41), (42), (43), (44), (45), (46) and (47), correspondingly) of the forthcoming strongest earthquakes (and related [4, 7, 8, 13-15, 17, 25, 31, 32] strongest volcanic, climatic and magnetic processes of the Earth) determined by the minimal (in 2018) combined planetary (of the Mercury, Venus, Mars and Jupiter) and solar (due to the gravitational interactions of the Sun with the Jupiter, Saturn, Uranus and Neptune) 
integral energy gravitational influence (6) on the internal rigid core $\tau_{c, r}$ of the Earth near the numerical time moment $\mathrm{t}_{*}\left(\tau_{\mathrm{c}, \mathrm{r}}, 2018\right)=2018.4$ corresponding approximately to 26 May, 2018.

Taking into account the confirmed validity of the previous prediction [31, 32] of the thermohydrogravidynamic theory (based on the established [8, 15] global prediction thermohydrogravidynamic principle (5)) concerning the strongest intensifications of the global natural processes of the Earth in 2016 since 1 September, 2016 [31, 32] and before 26 January, 2017 [32], taking into account the confirmed validity of the previous prediction of the thermohydrogravidynamic theory concerning the first subrange of the strongest intensifications of the global natural processes of the Earth in 2017 since 10 April, 2017 and before 6 August, 2017 [33, 34], taking into account "the confirmed validity of the predictions of the thermohydrogravidynamic theory concerning the strongest intensifications of the seismotectonic and climatic processes in California (since 9 August, 2017 and before 3 March, 2018) and in Japan since 24 July, 2017 and before 16 March, 2018" [40], and taking into account the presented (on 26 February, 2018) confirmed validity of the previous prediction of the thermohydrogravidynamic theory concerning the second subrange (since 6 August, 2017 (instead of 18 July, 2017 [23, 33]) and before 26 February, 2018 [23, 33]) of the strongest intensifications of the global natural processes of the Earth, the author suggests the reasonable applications of the founded forthcoming ranges ((48), (49), (50), (51), (52), (53), (54), (55), (56), (57), (58), (59), (60) and (61) characterized by the probabilities (34), (35), (36), (37), (38), (39), (40), (41), (42), (43), (44), (45), (46) and (47), correspondingly) of the first subrange (in 2018) of the strongest intensifications (since 26 February and before 24 August, 2018) of the global natural (seismotectonic, volcanic and climatic) processes of the Earth for the governments of the world-wide states to diminish (in advance) the devastating effects (in 2018) of the forthcoming natural catastrophic processes of the Earth in 2018. The additional argument to take into account the founded forthcoming ranges ((48), (49), (50), (51), (52), (53), (54), (55), (56), (57), (58), (59), (60) and (61) characterized by the probabilities (34), (35), (36), (37), (38), (39), (40), (41), (42), (43), (44), (45), (46) and (47), correspondingly) is the fact that the first direct detection [41] of gravitational waves (on September 14, 2015 [41]) was realized between the calculated date $\mathrm{t}^{*}\left(\tau_{\mathrm{c}, \mathrm{r}}, 2015\right)=2015.6833$ (corresponding approximately to September 6, 2015) and the date

(September 16, 2015 according to the U.S. Geological Survey) of the strongest (in 2015 according to the U.S. Geological Survey) 8.3-magnitude Chilean earthquake occurred near 9.92 days after the calculated date $\mathrm{t}^{*}\left(\tau_{\mathrm{c}, \mathrm{r}}, 2015\right)=2015.6833$ corresponding to the maximal (in 2015) combined planetary and solar integral energy gravitational influence (5) on the internal rigid core $\tau_{\mathrm{c}, \mathrm{r}}$ of the Earth.

\section{Acknowledgements}

The author thanks the Editor with gratitude for the editorial comments and corrections improving the final text of the article. The author thanks Mr. A.G. Starikov and Mr. P.E. Shsherbinin for the very constructive discussions.

\section{References}

[1] Charles Francis Richter. (1958). "Elementary Seismology.” San Francisco, USA: W.H. Freeman. 
[2] Sergey Victorovich Simonenko. (2013). "Fundamentals Of The Thermohydrogravidynamic Theory Of The Global Seismotectonic Activity Of The Earth." International Journal of Geophysics, 2013 (519829), 1-39. http://dx.doi.org/10.1155/2013/519829

[3] Sergey Victorovich Simonenko. (2014). "The Practical Forecasting Aspects of The Thermohydrogravidynamic Theory Of The Global Seismotectonic Activity Of The Earth Concerning To The Japanese Earthquakes Near The Tokyo Region." American Journal of Earth Sciences, 1(2), 38-61. http://www.openscienceonline.com/journal/archive2?journalId=715\&paperId=457

[4] Sergey Victorovich Simonenko. (2014). "The Linkage Of The Different Distinct Great Volcanic Eruptions Of The Thera (Santorini) In The Range $(1700 \div 1450 \pm 14)$ BC And The Related Subsequent Intensifications Of The Global Seismicity And Volcanic Activity In The End Of The 19th Century And In The Beginning Of The 20th Century, In The End Of The 20th Century, And In The Beginning Of The 21 st Century AD." Journal of Advances in Physics, 4(2), 484-516. http://cirworld.org/journals/index.php/jap/article/view/53N

[5] T. Simkin, L. Siebert, L. McClelland, D. Bridge, C. Newhall, and J. Latter. (1981). "Volcanoes of The World." Stroudsburg: Hutchinson Ross.

[6] Hubert Horace Lamb. (1977). "Climate: Present, Past And Future. Vol. 2: Climatic History And The Future." London, UK: Methuen.

[7] Sergey Victorovich Simonenko. (2009). "Fundamentals Of The Thermohydrogravidynamic Theory Of Cosmic Genesis Of The Planetary Cataclysms." Nakhodka, Russia: Institute of Technology and Business Press. https://www.researchgate.net/publication/281825324_Fundamentals_of_the_Thermohydrogravid ynamic_Theory_of_Cosmic_Genesis_of_the_Planetary_Cataclysms

[8] Sergey Victorovich Simonenko. (2012). "The Cosmic Energy Gravitational Genesis Of The Increase Of The Seismic And Volcanic Activity Of The Earth In The Beginning Of The 21st Century AD." Nakhodka, Russia: Institute of Technology and Business Press.

[9] i. K. Crain, P. L. Crain, and M. G. Plaut. (1969). "Long Period Fourier Spectrum Of Geomagnetic Reversals." Nature, 223 (5203), 283-283.

[10] Nils-Axel Mörner, J. P. Lanser, and J. Hospers. (1971). "Late Weichselian Palaeomagnetic Reversal." Nature. Physical Science, 234, 173-174.

[11] M. Barbetti, and M. McElhinny. (1972). "Evidence Of A Geomagnetic Excursion 30000 Yr BP. "Nature, 239(5371), 327-330.

[12] Reidar Løvlie. (1989). "Palaeomagnetic Excursions During The Last Interglacial/ Glacial Cycle: A Synthesis." Quaternary International, 3-4, 5-11. https://doi.org/10.1016/1040-6182 (89)90068-2

[13] Sergey Victorovich Simonenko. (2014). "The Evidence Of The Cosmic Energy Gravitational Genesis Of The Forthcoming Intensification Of The Global Seismotectonic, Volcanic, Climatic And Magnetic Activity Of The Earth, And The Problem Of The Controlled Thermonuclear Reactions." International Journal of Latest Research in Science and Technology, 3 (3), 206-214.

[14] Sergey Victorovich Simonenko. (2007). "Thermohydrogravidynamics Of The Solar System." Nakhodka, Russia: Institute of Technology and Business Press. https://www.researchgate.net/publication/228686707_OF_THE_SOLAR_SYSTEM

[15] Sergey Victorovich Simonenko. (2014). "The Prognosticating Aspects Of The Developed Cosmic Geophysics Concerning The Subsequent Forthcoming Intensifications Of The Global Seismicity, Volcanic And Climatic Activity Of The Earth In The $21^{\text {st }}$ Century." British Journal of Applied Science \& Technology, 4(25), 3563-3630. https://doi.org/10.9734/BJAST/2014/10766

[16] Sergey Victorovich Simonenko, and Vyacheslav Borisovich Lobanov. (2018). "The Application Of The Generalized Differential Formulation Of The First Law of Thermodynamics For Evidence Of The Tidal Mechanism Of Maintenance Of The Energy And Viscous-thermal Dissipative 
Turbulent Structure Of The Mesoscale Oceanic Eddies.” Journal of Modern Physics, 9, 357-386. https://doi.org/10.4236/jmp.2018.93026

[17] Sergey Victorovich Simonenko. (2014). "The Evidence Of The Cosmic Energy Gravitational Genesis Of The Possible Forthcoming Geomagnetic Reversal Of The Magnetic Field Of The Earth.” International Journal of Engineering Science and Innovative Technology, 3(6), 568-585. http://www.ijesit.com/archive/19/volume-3issue-6november-2014.html

[18] David J. Rose. (1971). “Controlled Nuclear Fusion: Status And Outlook.” Science, 172 (3985): 797-808.

[19] Pyotr Leonidovich Kapitza. (1978). "Plasma And The Controlled Thermonuclear Reaction. Nobel Lecture In Physics." Moscow, USSR: Institute for Physical problems of the USSR Academy of Sciences.

[20] "Progress In Fusion." (2014). ITER Organization.

[21] Sergey Victorovich Simonenko. (2006). "Non-equilibrium Statistical Thermohydrodynamics of Turbulence." Moscow, Russia: Nauka.

[22] Istvan Gyarmati. (1970). "Non-equilibrium Thermodynamics. Field Theory And Variational Principles.” Berlin, Germany: Springer-Verlag.

[23] Sergey Victorovich Simonenko. (2017). "The Prediction Of The Thermohydrogravidynamic Theory Concerning The Strongest Intensifications Of The Global Natural Processes Of The Earth Since 18 July, 2017 And Before 26 February, 2018." International Journal of Research Granthaalayah, 5(8), 127-145.

http://oaji.net/articles/2017/1330-1507200277.pdf

[24] Sybren Ruurds de Groot, and Peter Mazur. (1962). "Non-equilibrium Thermodynamics." Amsterdam, Holland: North-Holland Publishing Company.

[25] Sergey Victorovich Simonenko. (2015). "The Cosmic Energy Gravitational Genesis Of The Forthcoming Intensifications Of The Global Seismotectonic, Volcanic, Climatic And Magnetic Activities Since 2016 AD." American Journal of Earth Sciences. 2(6), 211-229. http://www.openscienceonline.com/journal/archive2?journalId=715\&paperId=3841

[26] Josiah Willard Gibbs. (1873). "Graphical Methods In The Thermodynamics Of Fluids." Transactions of the Connecticut Academy, 2, 309-342.

[27] Lev Davidovich Landau, and Evgeny Mikhailovich Lifshitz. (1976). "Theoretical Physics. Vol. 5. Statistical Physics." Moscow, Russia: Nauka. In Russian.

[28] Sergey Victorovich Simonenko. (2004). "The Macroscopic Non-equilibrium Kinetic Energies Of A Small Fluid Particle." Journal of Non-Equilibrium Thermodynamics, 29 (2), 107-123. https://doi.org/10.1515/JNETDY.2004.007

[29] T. Alboussière, R. Deguen, and M. Melzani. (2010). "Melting-induced Stratification Above The Earth's Inner Core Due To Convective Translation." Nature, 466, 744-747.

[30] Sergey Victorovich Simonenko. (2010). "Fundamentals Of The Thermohydrogravidynamic Theory Of Cosmic Genesis Of The Planetary Cataclysms." Second Edition. Nakhodka, Russia: Institute of Technology and Business Press.

[31] Sergey Victorovich Simonenko. (2016). "The Prognosticating Results Of The Cosmic Seismology Concerning The Forthcoming Intensification Of The Global Seismotectonic, Volcanic And Climatic Activities Of The Earth From 1 September To 10 November, 2016 AD." Journal of Advances in Environmental Sciences, 1(2), 90-101. https://cirworld.com/index.php/jes/article/view/4261

[32] Sergey Victorovich Simonenko. (2016). "The Confirmed Validity Of The Thermohydrogravidynamic Theory Concerning The Strongest Intensifications Of The Global Natural Processes Of The Earth In 2016 Since 1 September, 2016." British Journal of Applied Science \& Technology, 18(5), 1-20. Article no.BJAST.30049. http://www.journalrepository.org/media/journals/BJAST_5/2017/Jan/Simonenko1852016BJAST 30049.pdf 
[33] Sergey Victorovich Simonenko. (2017). "The Cosmic Gravitational Genesis Of The Predicted Intensifications Of The Global Natural Processes Since 10 April, 2017 And Before 26 February, 2018." American Journal of Earth Sciences, 4 (3), 32-47. http://www.openscienceonline.com/journal/archive2?journalId=715\&paperId=3841

[34] Sergey Victorovich Simonenko. (2017). "The Confirmed Validity Of The Thermohydrogravidynamic Theory Concerning The First Subrange Of The Strongest Intensifications Of The Global Natural Processes Of The Earth In 2017 Since 10 April, 2017 And Before 6 August, 2017." Transylvanian Review, XXV (20), 5049-5058. http://transylvanianreviewjournal.org/index.php/TR/article/view/1326

[35] Sofia Lotto Persio. "Yellowstone Supervolcano Earthquake Swarm Hits More Than 1,200 Events." Tech \& Science. July 20, 2017.

http://www.newsweek.com/yellowstone-supervolcano-earthquake-swarm-hits-over-1200-events639816

[36] Michael Safi. "India Floods: 213 Killed In Gujarat As Receding Waters Reveal More Victims." The Guardian. July 31, 2017. https://www.theguardian.com/world/2017/jul/31/india-monsoonfloods-gujarat-death-toll-over-200

[37] "Typhoon Noru Brings Heavy Rain To Japan, Injures 51." AFP. August 8, 2017. https://www.yahoo.com/news/typhoon-noru-brings-heavy-rain-japan-injures-51-064709046.html

[38] Rebecca Ratcliffe. "Floods Claim More Than 800 Lives Across India, Nepal and Bangladesh." The Guardian. August 22, 2017. https://amp.theguardian.com/global-development/2017/aug/22/floods-across-india-nepal-andbangladesh-claim-more-than-800-lives-south-asia

[39] Frank Bajak. "Damaging Hurricane Harvey Settles In Over Southeast Texas." Associated Press. August 27, 2017.

https://www.yahoo.com/news/damaging-hurricane-harvey-settles-over-southeast-texas082259260.html

[40] Sergey Victorovich Simonenko. (2017). "The Confirmed Validity Of The Predictions Of The Thermohydrogravidynamic Theory Concerning The Strongest Intensifications Of The Seismotectonic And Climatic Processes In California (Since 9 August, 2017 And Before 3 March, 2018) And In Japan Since 24 July, 2017 And Before 16 March, 2018." Current Science, 114 (7), 301-324. http://currentscience.org/index.php/CS/article/view/191

[41] Sanjeev Dhurandhar, and Bangalore S. Sathyaprakash. (2017). "Cosmic Sirens: Discovery Of Gravitational Waves And Their Impact On Astrophysics And Fundamental Physics." Current Science, 113 (4), 663-671. https://orca.cf.ac.uk/104679/1/0663.pdf

*Corresponding author.

E-mail address: sergeysimonenko@ mail.ru 